\title{
THE ROLE OF THE PROJECT MANAGEMENT OFFICE IN KNOWLEDGE TRANSFER IN A MATRIX- STRUCTURED ORGANISATION: A CASE STUDY
}

\author{
N. Gomo ${ }^{1}$, H. Steyn ${ }^{1}$ \& C.C. van Waveren ${ }^{1 *}$
}

\section{ARTICLE INFO}

$\begin{array}{lr}\text { Article details } & \\ \text { Submitted by authors } & 12 \text { Apr } 2021 \\ \text { Accepted for publication } & 4 \text { Oct } 2021 \\ \text { Available online } & \text { 14 Dec } 2021\end{array}$

Contact details

* Corresponding author corro@up.ac.za

Author affiliations

1 Department of Engineering and Technology Management, Graduate School of Technology Management, University of Pretoria, South Africa

\section{ORCID® identifiers}

N. Gomo

https: / /orcid.org/0000-0002-8969-1375

H. Steyn

https://orcid.org/0000-0002-5913-6354

C.C. van Waveren

https: / /orcid.org/0000-0002-2624-5247

\section{DOI}

http://dx.doi.org/10.7166/32-4-2517

\section{ABSTRACT}

The knowledge transfer role of a project management office in a matrixstructured telecommunication organisation was investigated by means of focus groups and interviews, and the results were analysed with ATLAS.ti software. The results confirmed the key role that the project management office plays in knowledge transfer. Corporate culture was found to have a greater effect on knowledge transfer than the type of organisational structure. Conflicts and other challenges typical of matrix structures did not necessarily hinder knowledge transfer, and even contributed to it. The knowledge transfer roles of the project management office were primarily perceived as a moderator of the transfer of technical information and a mediator of project and business knowledge.

\section{OPSOMMING}

Die rol van 'n projekbestuurkantoor ten opsigte van kennisoordrag in ' telekommunikasie organisasie met 'n matriks-struktuur is ondersoek met behulp van fokusgroepe en onderhoude. Die resultate is met ATLAS.ti sagteware ontleed. Die resultate bevestig die sleutelrol wat die projekbestuurskantoor in kennisoordrag speel. Organisasiekultuur het 'n groter rol as organisasiestruktuur gespeel, terwyl konflikte en ander probleme wat tipies met matriks-strukture geassosieer word nie noodwendig kennisoordrag benadeel nie, en selfs kennisoordrag bevorder. Die rol van die projekbestuur-kantoor in kennisoordrag is hoofsaaklik beskou as ' $n$ moderator van oordrag van tegniese kennis en 'n mediator in die geval van projek- en besigheidskennis.

\section{INTRODUCTION}

A customary error in project management is to assume that each project is unique, and so knowledge cannot be transferred between projects [1]. Owing to their temporary nature, projects focus on creating specific deliverables within a time limit; but insights from previous projects can often be gleaned and adopted in future projects. These insights can be recorded in the project documentation or be tacitly embedded in it by the project personnel. Knowledge transfer (KT) facilitates disseminating information between projects; but that facilitation requires favourable conditions [2], including an organisational structure that provides an environment for project processes. Such structures for project organisation can be classified as functional, matrix, or projectised [3].

Previous literature has focused on knowledge transfer in projectised organisations, probably because of concerns about their 'non-permanent' dynamics [4]. The matrix structure remains popular in most organisations as an alternative to the functional structure and the projectised organisation [5]. According to Bannerman [6], matrix structures have inherent challenges that are specific to each design. It cannot be assumed that the function of the PMO in knowledge transfer for a specific structure mimics its function in other structures. This paper therefore explores how a project management office (PMO) functions in the knowledge transfer process of a matrix organisation.

Project knowledge transfer is the process of converting personal information and experience into collective knowledge, focusing on administering a project while drawing on prior related experiences. The knowledge 
is either tacit (implied or understood without being articulated) or explicit (communicated or expressed in symbolic form) [7]. Knowledge is captured, especially in project closeout and project review meetings, during the conclusion of projects or project phases [1]. This process is followed by storing the distributed knowledge, thus completing the transfer process [8].

Tacit (intuitive and unarticulated) knowledge can also be converted into explicit forms to ensure transferability (Nonaka and Takeuchi, 1995, as cited in [2]). Social interactions exemplify this phenomenon in the form of meetings or face-to-face conversations that are perceived as channels for converting tacit knowledge into explicit knowledge, and its eventual transfer between organisations with diverse knowledge [9].

\section{THE MATRIX ORGANISATIONAL STRUCTURE}

Functional structures are characterised by 'functional silos' with an internal and specialised focus on an area of expertise. Interdepartmental coordination is insubstantial, while knowledge sharing and communication across functional boundaries is minimal [10]. On the other hand, in the projectised organisation, projects are autonomous and independent of the functional areas, and the members of project teams are detached from the functional hierarchy [11].

Functional and projectised organisational structures have morphed to create a matrix organisation. According to Galbraith [12], the advent of the matrix organisation is a result of the need to address crossfunctional challenges. Matrices are vertically established functional teams with the horizontal overlay of the projects, providing dual authority and reporting lines [13]. On the one hand, there is the functional manager, and on the other, the project manager (PM). The matrix structure keeps a delicate balance with a duality of command, which presents implementation and operational challenges [14]. These challenges include the allocated authority and role of the project manager, availability and access to resources, control over the allocated budget, and the allocation of project administrative staff [15].

\section{THE PROJECT MANAGEMENT OFFICE}

According to Monteiro et al. [16], the project management office (PMO) is "an organisational structure created to promote and improve project management practice by adopting appropriate methodologies to achieve high levels of efficiency and effectiveness". Its primary goal is to support and assist project managers (PMs), facilitating good project management practice and overseeing knowledge management [1]. PMOs are structured and mandated along with the needs of the organisations where they function; thus no two PMOs are similar [17]. A perspective on the role of the PMO clarifies its relational, social, and organisational structures. It focuses on the interactions and interdependencies between various functions, projects, and organisational units [18].

In its function as a knowledge broker, the PMO develops and maintains established standards and methods, providing centralised archives of systematically collected and stored project knowledge [19].The PMO also provides some form of organisational coordination, support, and procedural knowledge concerning reporting, how to act in a project, and how to follow project management practices concerning some of the necessary tools and systems to conduct projects. These might include project management standards, templates, and guidelines on how to conduct projects and prepare technical guidelines, checklists, and manuals [20].

According to Tshuma et al. [21], the PMO can perform moderating and/or mediating roles when transferring knowledge between functions or projects. These roles depend on the availability of knowledge transfer infrastructures and processes. Müller et al. [18] employ the typology of a broker and a steward, emphasising the relational role of the PMO. The PMO's role in knowledge transfer can thus be summarised as follows:

- $\quad$ Moderation role ('the steward'): The PMO plays a supportive role in providing infrastructure and processes for knowledge transfer between projects.

- Mediation role ('the broker'): The PMO participates in facilitating transferring knowledge between projects. This involving retaining and enhancing the knowledge obtained from one project before relaying it on to the next project. 
The objective of this research was to investigate the role of the PMO and functional managers in transferring knowledge in a matrix structured organisation. A telecommunications company based in Southern Africa was the focus of this case study. In support of the objective, two research questions are defined namely:

1. What role does the PMO play in the case organisation to promote the transfer of knowledge between projects and functional areas of the matrix organisation?

2. How do the challenges, as perceived by matrix organisational structures, influence knowledge transfer in the case organisation?

\section{THE PROPOSED CONCEPTUAL MODEL}

The dual reporting in a matrix structure often leads to conflict, and project personnel experience the overlap in responsibility and authority when their functional departments interact with the project manager during projects [14]. The PMO therefore has the potential to act as an interface, and can function as a bridge across organisational and knowledge boundaries in project-based organisations [22], [23]. Tshuma et al. [21] confirm that the facilitation and support provided by the PMO is crucial to knowledge transfer between projects. This position is established for a PMO in a project-based organisation, and so there is a need to explore the equivalent in a matrix organisation.

The inventory of knowledge used in projects is classified into three main knowledge groupings: business knowledge, technological knowledge, and project management knowledge. These knowledge grouping are defined below, and are applicable throughout the duration of the project or of multiple projects [4].

- $\quad$ Business knowledge: Also known as market knowledge, it relates to understanding market conditions and trends to identify and align projects that could be considered as part of the project portfolio to increase business value.

- Technological knowledge: Also known as specialist, product, or scientific knowledge, this relates to, is the heart of, and forms the foundation for a product or service. It is the technical knowledge of a project's deliverable(s).

- $\quad$ Project management knowledge: This knowledge focuses on how to plan, organise, execute, and control a project, applying all the different project management knowledge subject areas, together with the ability to integrate the various concepts, activities, capabilities, and products while drawing from prior or related experiences.

In project management, the concept of functional areas was applied to the labour division between project operations and the project client interface [18]. In addition, each functional area may exhibit all three knowledge groupings, although the strength and focus of each grouping may differ between functional areas. Figure 1 illustrates the proposed research model, indicating the PMO's roles and the knowledge flows between the PMO and the functional areas (the mediating role) and between functional areas (the moderating role); and each functional area overlaps with the project, as indicated by the larger circle, and with the organisation. 


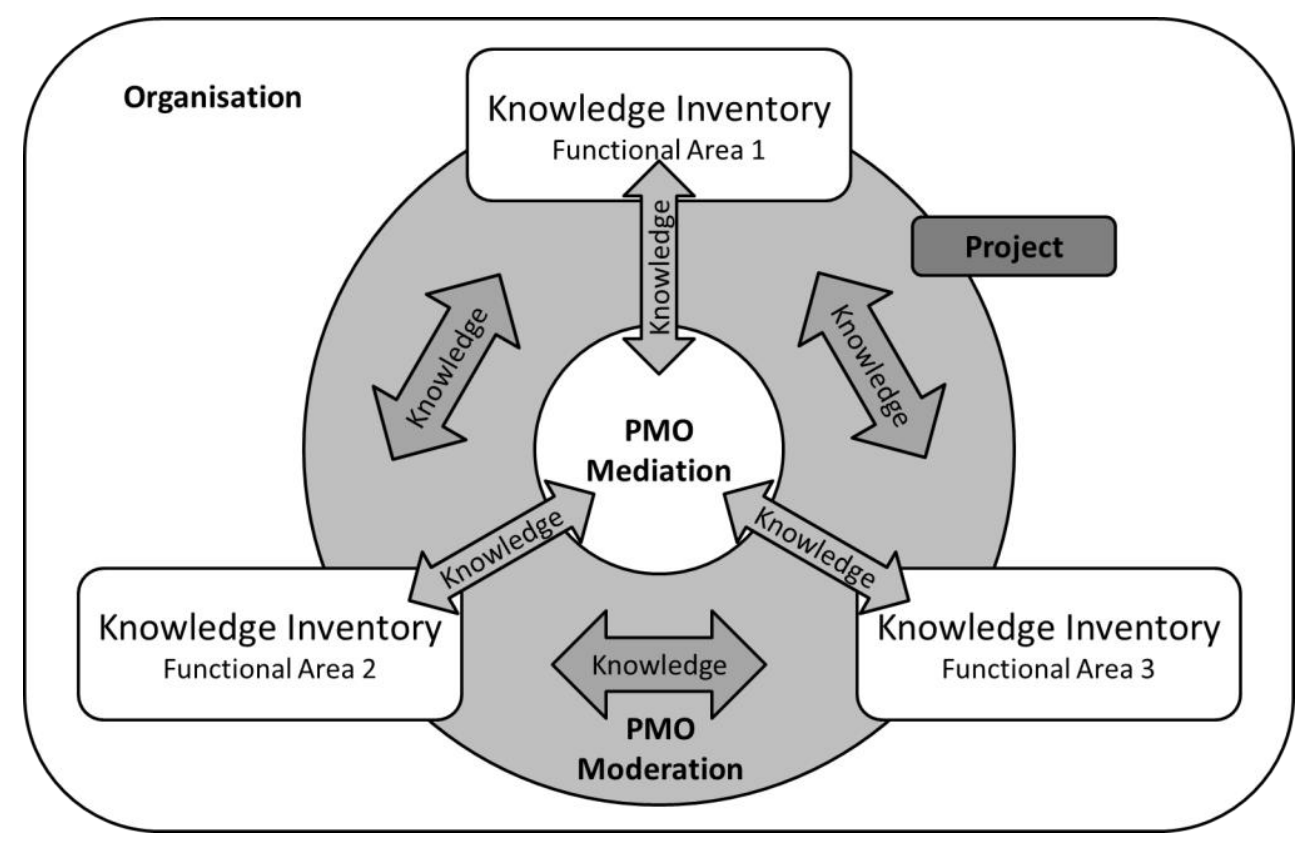

Figure 1: Conceptual model

Transfer mechanisms are used by the PMO and the functional areas to assist with the transfer of knowledge between the project, the functional areas, and the organisation [24], while the resources provide the required content and context for the knowledge that is transferred [25].

The propositions below are derived from the literature and the conceptual model to answer the research questions:

- $\quad$ Proposition 1: Challenges associated with the matrix structure affect knowledge transfer in a matrix organisation.

- $\quad$ Proposition 2: Knowledge transfer roles depend on the organisational structure.

- Proposition 3: The PMO acts as the knowledge broker and steward in knowledge transfer in the case organisation.

- $\quad$ Proposition 4: Functional boundaries are rigid by default, and are only permeable through the PMO's mediation and moderation.

\section{THE CASE ORGANISATION}

The case organisation has been in existence for over 20 years, and has positioned itself as a leading telecommunications provider in the Southern African region. In that period, it has garnered a subscriber base of over 12 million connected customers. It has a staff complement in excess of 2000 employees, and operations in several Southern African countries. The company's thrust is to maintain its national market dominance through innovative and pioneering technology and a sustainable, well-governed business model.

The company's main segments are its mobile network operations and its financial technology services. The financial services segment includes mobile money services and payment solutions. While mobile telecommunications is its core business, it has created a platform for the organisation to provide overlay services that extract value from the existing infrastructure. The case organisation's strategy is focused on consistently leading in innovation, product development, and service delivery.

The company is structured as a strong matrix organisation with staff who are dedicated to work full-time on projects and who constitute the PMO. The PMO works with the functional departments' resources for project delivery. While these are assigned by the functional managers, they report to the project manager (PM) on project-specific tasks. However, the assigned resources are still expected to perform some of their legacy functional responsibilities. The PMs have programme managers and a portfolio management executive that provides leadership for the enterprise's PMO. The enterprise-wide mandate of the PMO means that projects that are undertaken are varied because of the multi-layered focus of the company. 
Projects include civil construction, administration, software development, new product development, technology deployment, and enterprise transformation. These assorted projects primarily make use of SharePoint, internal databases, and Qlik Sense to store and access the lessons learnt and other related project documentation. Gitlab and Jira have been popular with software development projects.

\section{RESEARCH APPROACH}

The case study method was used. A case study is an in-depth inquiry into a topic or phenomenon in its actual surroundings (Yin, 2014, cited in [26]). Case study research is also suitable for contemporary events when the relevant behaviour cannot be manipulated [27]. It provides a vantage point from which to produce context-dependent knowledge [28]. The research focuses on a specific company, and so it can be classified as a single case study. Because of time constraints, the research was a cross-sectional study. Saunders et al. [26] describe such a study as observing a particular phenomenon at a particular time, as opposed to a diary perspective, which creates multiple views over time.

A multi-method qualitative study was selected to collect data from the case organisation. This approach employs various data collection techniques for the qualitative study [26]. The following techniques were selected for this study:

- $\quad$ Focus group interviews were conducted for project team members, with introductory semi-structured questions to probe potential areas to explore in depth in the case organisation. Two focus groups with six members each were selected.

- Tier 1 interviews were scheduled and conducted on a one-on-one basis with some of the project managers, PMO staff, and functional managers. This created an opportunity to pose questions on themes that emerged in the focus groups, along with semi-structured interview questions. Three project managers, three functional managers, and two PMO staff members participated in the interviews. The selection of the project managers and functional managers was based on their being the chief protagonists in the matrix organisation. The PMO staff were included to capture fully the function of the PMO beyond the duties of the project manager.

- $\quad$ Tier 2 interviews were then scheduled with the technical director and the portfolio management executive to provide a panoramic view of all the themes, with a better and in-depth understanding of the strategy from an executive level.

\section{$7 \quad$ RESULTS}

All of the interviews with the individuals and the groups were recorded, transcribed, and coded into themes using the ATLAS.ti qualitative data analysis software tool. From the interviews, 16 themes were identified that described the relationships between the PMO, the projects, and the functional areas in the matrix structure of the case organisation. These themes are shown in Table 1. It should be noted that the discussion of the themes was conducted according to the organisational or management level, not according to the theme itself; thus readers can readily identify themselves with the appropriate organisational or management level and the important themes associated with that level.

Table 1: Identified themes

\begin{tabular}{|l|l|}
\hline \multicolumn{2}{|l|}{ Themes } \\
\hline Roles in knowledge transfer & Organisational culture \\
\hline Knowledge transfer & Moderation role in KT \\
\hline Knowledge transfer challenges & Interdepartmental flow of information \\
\hline Conflict in knowledge transfer & Knowledge transfer maturity \\
\hline Conversion of tacit to explicit knowledge & Trust in knowledge transfer \\
\hline Mediation role in KR & Reporting lines \\
\hline PMO mandate & Task prioritisation \\
\hline Matrix structure & Training \\
\hline
\end{tabular}

\subsection{Focus groups}

Focus groups identified the initial themes, which included roles in knowledge transfer, the matrix structure, mediation, moderation, conflict in knowledge transfer, and the organisational culture. Probing questions focused on the conflict in the matrix organisation, and were used to probe the emergence of any themes not captured in the semi-structured questions. No new themes emerged. 
The first focus group (FG1), contrary to expectations, experienced little to no conflict between the PMO and the functional teams. This was in contrast with the second focus group (FG2). As one of the respondents from FG1 said: "Most of our functional work is related to the project work that is ongoing" (FG1-b).

Certain members of FG1 acknowledged experiencing pressure, attributable to the 'double-hat' phenomenon (a manager playing both project manager and functional manager roles) and of expectations from the functional and PMO establishments. The general sense within the focus groups indicated the need for clearer lines of reporting and for greater clarity on prioritising between project operations and functional operations. This was explicitly captured by one of the respondents as follows: "When the PM requests something directly from the engineers without the manager knowing it, [it] puts so much pressure on the engineers. The manager might also assign something not project-related to us" (FG1-c).

The focus groups identified the organisational culture as a potential deterrent to knowledge transfer. FG1 listed concerns with a legacy approach that viewed functional teams as silos, according to their expertise; while FG2 raised concerns about trust and job security as deterrents to a knowledge sharing culture. One respondent expressed his fears on the subject: "You still want to be the subject matter expect for some issues" (FG2- a).

Although the culture might have been influenced by previous structures, from the recollections that were shared it was not directly attributable to the matrix structure. A respondent in FG2 identified crossfunctional teams as enablers of an unconstrained flow of information. He made the following remark: "I think the cross-functional team presents an opportunity as it sort of forces you to engage and collaborate as a team" (FG2-d).

FG1 and FG2 identified the lessons learnt meetings as rewarding for the project team and for the PMO. Both groups raised concerns about their not being privy to the specific project teams, and meetings were often too few and far between to enable the efficient capturing of any new knowledge. On identifying the function of the PMO in the knowledge transfer process, a member of FG2 suggested that knowledge transfer was made necessary more by collaboration among the individual team members rather than by facilitations by the PM: “...knowledge transfers occur, but not intentionally” (FG2-a).

This was not, however, a popular sentiment among all of the members of the focus groups. The experiences of other participants alluded to the cross-functional teams as pivotal in providing project team members with novel insights. Therefore, restraining these project team members' contributions in the knowledge generation, retention, and transfer processes should be avoided. The following were identified as the main knowledge transfer challenges for both focus groups:

- The formality required in transferring knowledge is a deterrent, especially for tacit knowledge. As one respondent put it: "...information sharing can be improved through informal processes. You can see that it's more effective!" (FG1-e).

- Where the focus is on 'my' task, the silo mentality can spread into the cross-functional teams.

The focus groups failed to identify deliberate efforts from the PMO to capture tacit knowledge. It was acknowledged that training occurs, but that it might not lead fully to the desired transfer of embedded expertise. They also identified their functions in the knowledge transfer process as primarily knowledge generation and capturing. Design and solution documents, which form part of technical knowledge, were their greatest artefact. As one respondent noted: "Our main role is to ensure the design documents are there and [are] updated" (FG1-b).

Project and entrepreneurial knowledge were not as pronounced in their responses. They perceived the PMO as providing a supportive function in knowledge transfer. The perception of the PMO as primarily a moderator could have been fostered by participants' bias towards technical knowledge. The PMO rarely alters these documents, but provides support through processes and systems for dissemination.

\subsection{Tier 1: Functional managers}

Regarding concerns about conflict between the PMO and the functional teams, there was no outright acknowledgement of its existence. Functional manager 1 (FM1) said that there was no conflict between the functional teams and the project teams in the case organisation. FM1 said that, although their priorities differed, they were not necessarily misaligned: "There is a lot of collaboration amongst our teams. We are driving towards the same goal" (FM1). 
Functional manager 2 (FM2) and functional manager 3 (FM3) referred to conflict in the past tense, indicating that it was not a current reality for them. When describing this changed position, reference was made to "maturity" - a theme mentioned by FM1 and FM3. This was stated as follows: "I think we have matured from that position. I don't remember anything happening that can prove otherwise" (FM3).

This theme was not previously captured on interacting with the focus groups. For this research it was identified as 'knowledge transfer maturity', although it was directly described as 'process maturity'. The impression is one of a matured organisation with trusted processes. All of the functional managers (FMs) were clear about their contributions to knowledge transfer in the organisation. Reference was especially made to technical knowledge in the form of solution documents generated by functional teams and knowledge bases concerning fault resolution. As one functional manager exclaimed: "KT is critical to [the] success of projects because you need to all be working towards the same cause or results. For you to have [a] smooth functioning of two discrete entities you need to have smooth transfer from one entity to the next!" (FM2).

FM1 acknowledged the function of PMs in encouraging collaboration, while there was consensus among all of the other FMs about the facilitation functions of the PMO. In contrast to the focus groups, all of the FMs believed that reporting lines were clear and should not be a source of ambiguity. As stressed by one FM: "When the project starts, my role is to provide the skills requested by the PMO. I allocate the resources and am aware of their involvement in the project" (FM1).

While the focus groups did not dwell on the devices that were available for the knowledge transfer process, the FMs emphasised their existence. FM3 bemoaned the inconsistent or non-extensive use of certain information system tools, such as the SharePoint ${ }^{\mathrm{TM}}$ application.

All of the FMs identified their functions in the knowledge transfer process. FM1 and FM2 identified technical and entrepreneurial knowledge capturing and storage as their foremost responsibility. FM3 agreed with the other two, while emphasising the importance of functional teams sharing project knowledge during project closure meetings: "We play a role in the creation of knowledge through the solution documents for the projects. Sharing our experiences can only improve how we do things" (FM3).

All of the FMs saw the PMO as providing a primarily supportive role in transferring knowledge during moderation. This position could be the result of their bias towards technical and entrepreneurial knowledge. It could also be speculated that acknowledging the mediation function of the PMO would be see as it is losing its relevance. The FMs thus identified the PMO as a steward more than as a broker.

\subsection{Tier 1: PMO staff and project managers}

The project managers (PMs) listed the non-permanence of allocated project resources as not ideal for knowledge transfer. This scenario makes it a common practice for various resources to enter the project at various stages. As one PM observed: "Sometimes the resources are dynamic. In a project, you can start with resource $A$, but by project closure you might have changed that resource three times for the same role. It's very difficult to manage knowledge transfer properly because in some cases the resources that leave the project might leave with some [tacit] knowledge" (PM1).

Project manager 1 (PM1) identified this as a unique opportunity to acquire the most experienced resources in good time to transfer some of their expertise and possibly convert some of the tacit knowledge into explicit knowledge. This still presents a challenge, as the change of resource would cause perceived syncing delays. According to PM1, the organisational culture can also override the designed structure: reference was made to the 'silo mentality' - an identified challenge to knowledge transfer. This mentality, however, is characteristic of purely functional organisations, as was evident in the strong matrix case organisation. Project manager 2 (PM2) referred to the silo approach as "coming up now and again as one of the greatest antagonists to knowledge transfer". It was summarised as follows: "Conflict arises and will be with us until a new culture is ingrained in all of us" (PM2).

PM2 acknowledged the existence of conflict with the functional teams, which he attributed to the unclear demarcation of functions. This resulted in 'pulling back' by the clashing teams if they sensed encroachment on what they perceived as their domain. "The bad thing about conflicts is that people pull back. There is always an overlay of where they think their jurisdiction ends" (PM2).

All of the other PMs concurred that conflict existed, but that it only occurred "sometimes". PM2 referred to adopting DevOps ${ }^{T M}$ and the strong matrix structure as empowering the dissemination of information. The 
PMO staff emphasised that functional teams failed to prioritise project tasks, resulting in delays to projects, potentially undermining its business case. This sentiment was expressed as follows: "Some of the resources we borrow are from an operations environment where they have to support live systems. Often times maintaining this (function) is more important to the resource. Not prioritising the project then results in delay" (PMO-a).

The uniqueness of a project was identified as facilitating knowledge transfer, with PM2 alluding to a high degree of applicability: "In the disruptive domain where we now operate there might be very little similarities between projects but lessons learnt are still valuable" (PM2). Project manager 3 (PM3) believed the disruptive technology space has diminished the degree of applicability.

PMs identified additional challenges, such as the inadequate documentation of project processes and an insufficient number of solution documents by project teams.

All of the PMs identified lessons learnt meetings as most crucial in aiding the knowledge transfer process. PM1 suggested that knowledge transfer is best handled if the PM deliberately includes the knowledge transfer plan in the project initiation stages: "There is need to have a knowledge transfer plan. It's the best way to deal with knowledge transfer" (PM1).

PM2 referred to knowledge transfer as a process requiring buy-in, in which the PM's involvement is needed to facilitate the necessary engagements among the team members and to encourage collaboration and support. All of the PMs identified their function as pivotal in anchoring the knowledge transfer process. The extent of championing this process varied. PM1 identified his participation as follows: " $80 \%$ of my time is spent on moderation while the $20 \%$ is spent on the mediation, mainly facilitation and document creation" (PM1).

PM3 believed that the FM has a more significant moderation function than the PM, who should focus on mediation. This view on the issue was confirmed by PM2: "There is more of mediation to be done especially in engaging vendors. An example is working with a supplier with minimum or no documentation" (PM2).

All of the PMs agreed that knowledge transfer is crucial to the success of any project. The PMO staff agreed with this view. The PMs identified their project processes as aiding knowledge transfer for the case organisation. Project initiation documents ensured that the lessons learnt or the knowledge database was queried when each new project initiation document was created. On capturing the lessons learnt, a PMO remarked: "The process mandates the documentation of the lessons learnt which form part of a mandatory artefact" (PMO-b).

By including the reference to a knowledge base when initiating new projects, the PMO enforced accessing the knowledge repository. Deliberate knowledge transfer planning is also manifested through scheduled training and shadowing, among other activities. However, consensus was lacking on the sufficiency of these approaches to capture tacit knowledge. PM1 and PM2 believed that the deliberate conversion of tacit knowledge to explicit knowledge was lacking, while PM3 believed that these processes fulfilled the mediating function of the PMO: "We have had instances where we faced challenges of ensuring smooth knowledge (tacit) transfer, but we addressed those by putting clear laid out processes to facilitate handover" (PM3).

The PMs and the PMO staff identified their roles in knowledge transfer as both knowledge brokers (mediators) and knowledge stewards (moderators). Individuals' perceptions varied on identifying whether the mediator or the moderator had the strongest role. The PMs and the PMO staff valued all knowledge equally, giving examples to illustrate their understanding. The PMO staff showed a greater appreciation for business knowledge, possibly attributable to their role in business analytics. Their awareness of their mediation function could have stemmed from articulating their mandate and knowledge transfer practice.

\subsection{Tier 2: Technical director}

According to the technical director, the PMO is mandated with portfolio management and service delivery, comprising:

- $\quad$ Attaining and translating business strategies and requirements.

- $\quad$ Prioritising requirements into portfolio pipelines and business plans.

- $\quad$ Diagramming project delivery.

- $\quad$ Delivering projects. 
Knowledge transfer is crucial in accomplishing this mandate, as stated by the technical director: "Knowledge transfer is the oil that is required for service enablement and project delivery to happen seamlessly" (Technical director).

With a business strategy that was aimed at delivering value and not only platforms, the director considered the PMO as crucial in the strategic transformation of the case organisation, and that it would need to be competent in capturing and transferring knowledge to achieve this mandate: "We are inherently looking at organisational transformation; this cannot happen without knowledge transfer" (Technical director).

The technical director emphasised documentation as being critical and crucial. The director also noted that the reluctance to share knowledge was a challenge to knowledge transfer, and that conflict occurred within the matrix structure. However, the technical director referred to past conflicts as positive because they generated knowledge while also advancing the case organisation: "Whenever there is some form of conflict it impacts how people work or relate to each other. When there is a conflict there is both a positive impact on knowledge transfer as well as a negative impact. Sitting down to resolve conflict has surfaced new knowledge for the organisation and improved it" (Technical director).

This optimistic feedback suggested the need to reconsider the effect of perceived conflict in the matrix structure. The adoption of a DevOps ${ }^{T \mathrm{M}}$ model in countering the traditional functional silos and implementing an agile methodology helped the case organisation's evolution. The technical director also mentioned that knowledge transfer fitted seamlessly into the corporate strategy, and that the PMO was mandated to facilitate this process.

\subsection{Tier 2: Portfolio management executive}

The portfolio manager identified the following as crucial to the PMO's mandate and its role in knowledge transfer:

- Quality checkpoints help to ensure that documentation is obtained with every milestone. This confirms the PMO as knowledge mediators and moderators and knowledge generators. This documentation drive is necessitated by the realisation that past project knowledge is a critical resource for the success of future projects, despite the uniqueness of projects: "Project delivery approach documentation is important .... What is also of importance is the technical documentation of the solution" (Portfolio manager).

- There are occurrences of conflict with functional teams. Early engagement in a project facilitates helps to establish common ground, speeding up the project's success and providing solutions: "If there is no early engagement of relevant stakeholders, delays can be up to six months" (Portfolio manager).

- Matrix structure conflicts arise from resourcing issues. The resources being used for the project work and the functional/operational work must have their roles and time defined to set expectations with the FM: "As long as they are assigned to a project, what they are going to do and the constraint of time in which they must do it has to be clearly defined. If they understand the expectation they will comply" (Portfolio manager).

- In line with to concurrent engineering, the widely held belief is that early involvement provides clarity and facilitates knowledge transfer across teams. While this is effective, the executive mentioned scope creep and prolonged decision-making as potential threats that arise from these early engagements.

- Accessibility is crucial in disseminating information, according to the portfolio manager. The PMO facilitated open forum engagements and supported employing various knowledge transfer information-sharing tools to provide for this process. A repository exists on SharePoint ${ }^{\mathrm{T}}$ : "Any good PMO should have project artefacts stored in some of a library for future referencing" (Portfolio manager).

- The PMO in the case organisation holds an end-to-end mandate, from the business concept to implementing the strategy. The PMO translates the business strategy and its requirements. This is clearly a mediation role. Mediation is crucial in collecting the requirements for professionally delivering projects. The mediation function is also involved in translating what success means for the stakeholders. The PMO mediates in the deployment of solutions. This was described as follows: “... most requesters have an idea of what they want but often face challenges articulating it!... We will have to sit down and understand what the requester wants and what the business strategy is" (Portfolio manager).

- According to the portfolio leader, the responsibility for documentation (project delivery approaches, sign-offs, contracts, closures, and tracking) rests squarely with the PM. The PM should also moderate in ensuring the repository's availability when a solution is operationalised. 


\subsection{Support for propositions}

Proposition 1: Challenges associated with the matrix structure affect knowledge transfer in a matrix organisation.

It was observed that the challenges related to the matrix structure influenced knowledge transfer in the case organisation. The study's results supported this proposition for the organisation that was studied. The challenges experienced according to the technical director created opportunities to engage personnel deliberately across teams. This had the effect of improving collaboration and so too the knowledge transfer process. Issues were raised about the 'silo mentality' that is inherently found in functional teams. This was discussed as a potential trust-related challenge. In addition, conflict in the matrix structure did not hinder knowledge transfer, as the conflicts in operations were not cascaded down to the knowledge transfer process. In fact, conflict-initiated knowledge creation and provided a basis for organisational improvement. The finding was that the organisational culture had a greater impact on knowledge transfer than the organisational structure. Conflict and challenges did not necessarily hinder knowledge transfer in the case organisation. This was attributable to the organisational culture and its ability to practise early engagement and resolution. The PMO was crucial in this process, thus departing from what was expected. Contrary to what was anticipated, the conflict and the challenges in the matrix structure actually enabled knowledge transfer. However, the issues to do with trust and knowledge transfer maturity were identified as hindrances to knowledge transfer. These were found to be related more to the organisational culture than to its structure.

\section{Proposition 2: Knowledge transfer roles depend on the organisational structure.}

The results of the research partially supported this proposition. This was established as true for the functional departments, while, for the PMO, specific functions were established to transcend the organisational structure differences. The functional departments' knowledge transfer activities were bound by their process and procedures. These in turn were heavily dependent on the organisational structure. The knowledge mediation and moderation roles of the PMO in the case organisation were established to be similar to those defined in the literature relating to project-based organisations. It was observed that the mediation role of the PMO was understood by both the executives and the PMO. However, the functional teams saw the PMO primarily as a moderator of knowledge transfer. The functional team's perception of knowledge could have influenced this as remaining primarily technical.

\section{Proposition 3: The PMO acts as the knowledge broker and steward in the knowledge transfer process.}

The study supported the notion of the PMO as both steward and broker of the knowledge transfer process. However, there were differences about which of the two was the more prominent role in the case organisation. The focus groups and the FMs emphasised the moderation function, while the executives and the PMO personnel acknowledged both functions. It is interesting to note that the perception of the role was determined by the type of knowledge. The PMO was perceived to act as a moderator for technical knowledge and as a mediator for project and business knowledge. This proposition held true in the matrix organisation being investigated.

Proposition 4: Functional boundaries are rigid by default, and are only permeable through the PMO's mediation and moderation.

The results supported this proposition. The PMO enhanced cross-functional team collaboration during project execution. It also played a moderating role by supporting knowledge transfer across departments. This knowledge would not have been transferred without the involvement of the PMO. The PMO translates business strategy and requirements for the functional teams, which is clearly a mediation role, helping requesters to articulate and capture project requirements. The PMO also mediates in the deployment of solutions.

\section{CONCLUSION}

The PMO was established to play a crucial role in the knowledge transfer process of the case organisation. The creation of cross-functional teams for collaboration was also identified as a unique function facilitated by PMO mediation. In agreement with the literature and the four propositions, the role of the PMO in a matrix was established to be that of mediation and moderation in the transfer of knowledge. Challenges and conflicts were instrumental in defining roles to ensure that knowledge transfer occurred, and had both 
positive and negative effects in the case organisation, contrary to the expectation that there would only be negative effects. The PMO in the matrix structure encountered different challenges from those experienced by PMOs in project-based organisations. These were previously chronicled in knowledge transfer investigations. Despite the difference in systems, the function of the PMO in facilitation and moderation did not change, but was enhanced to provide early engagement and conflict resolution.

The findings of this study create opportunities for further studies, such as why the different functional teams primarily observed the PMO as a moderator rather than as a mediator. A quantitative study could be conducted in such a case to identify the more dominant function. This could be further explored in the light of the structure of the organisation mandating the PMO. In this study, the PMO was depicted as a link in a matrix organisation, linking cross-functional teams and other collaboration initiatives. It was also found that conflict resolution in the case organisation created knowledge while also fostering the evolution of the organisational structure. Investigating the conflict resolution role of the PMO in a matrix structure could also be a future prospect to consider. Last, the organisational culture was an important theme, and was identified as a crucial factor in successful knowledge transfer in the case organisation because the team members and the project and functional managers had to put their personal preferences aside, trust one another, and collaborate as a team. The finding was that the organisational culture had a greater impact on knowledge transfer than the organisational structure. The effect of organisational culture on successful knowledge transfer could be investigated in the future.

\section{REFERENCES}

[1] J. M. Nicholas and H. Steyn, Project management for engineering, business and technology, 5th ed. Routledge, 2017.

[2] A. Hartmann and A. Dorée, "Learning between projects: More than sending messages in bottles," Int. J. Proj. Manag., vol. 33, no. 2, pp. 341-351, Feb. 2015.

[3] Project Management Institute, $A$ guide to the project management body of knowledge (PMBOK ${ }^{\circledR}$ Guide), 5th ed. Project Management Institute, 2013.

[4] C. C. van Waveren, L. A. G. Oerlemans, and M. W. Pretorius, "Knowledge transfer in project-based organizations: A conceptual model for investigating knowledge type, transfer mechanisms and transfer success," in IEEE International Conference on Industrial Engineering and Engineering Management, 2014, pp. 1176-1181.

[5] R. Schnetler, H. Steyn, and P. J. van Staden, "Characteristics of matrix structures, and their effects on project success," South African J. Ind. Eng., vol. 26, no. 1, pp. 11-26, 2015.

[6] P. L. Bannerman, "Structuring risk into projects," in Proceedings of the PMI Research Conference: Defining the Future of Project Management, Washington DC, 2010.

[7] M. Alavi and D. E. Leidner, "Review: Knowledge management and knowledge management systems: Conceptual foundations and research issues," MIS Q., vol. 25, no. 1, pp. 107-136, 2001.

[8] S. McClory, M. Read, and A. Labib, "Conceptualising the lessons-learned process in project management: Towards a triple-loop learning framework," Int. J. Proj. Manag., vol. 35, no. 7, pp. 1322-1335, 2017.

[9] H. Kasper, M. Lehrer, J. Mühlbacher, and B. Müller, "On the different 'worlds' of intra-organizational knowledge management: Understanding idiosyncratic variation in MNC cross-site knowledge-sharing practices," Int. Bus. Rev., vol. 22, no. 1, pp. 326-338, 2013.

[10] I. Todorović, M. Čudanov, and S. Komazec, "Improvement of organizational knowledge transfer through integration of functional silos in smart network: Case study of public enterprises," in Knowl. Manag. Compet. Advant. Dur. Econ. Cris., P. Ordoñez de Pablos, L. Turró, R. Tennyson, and J. Zhao, Eds. pp. 299-309, 2015.

[11] L. Čondrić, D. Dech, and D. Galić, "The importance of project office in matrix organization," in Proceedings of the 8th International Conference on Telecommunications, ConTEL 2005, 2005, pp. 671-675.

[12] J. R. Galbraith, "Matrix organization designs: How to combine fucntional and project forms," Business Horizons, vol. 14, no. 1. pp. 29-40, 1971.

[13] P. L. Bannerman, "Risk implications of software project organization structures," in Proceedings of the Australian Software Engineering Conference, ASWEC, 2009, pp. 307-316.

[14] D. Moodley, M. Sutherland, and P. Pretorius, "Comparing the power and influence of functional managers with that of project managers in matrix organisations: The challenge in duality of command," South African J. Econ. Manag. Sci., vol. 19, no. 1, pp. 103-117, 2016.

[15] Project Management Institute, A guide to the project management body of knowledge (PMBOK Guide ${ }^{\circledR}$ ), 6th ed. Project Management Institute, 2017.

[16] A. Monteiro, V. Santos, and J. Varajão, "Project management office models: A review," Procedia Computer Science, vol. 100, pp. 1085-1094, 2016.

[17] J. van der Linde and H. Steyn, "The effect of a project management office on project and organisational performance: A case study," South African J. Ind. Eng., vol. 27, no. 1, pp. 151-161, 2016.

[18] R. Muiller, J. Gluickler, and M. Aubry, “A relational typology of project management offices," Project Management Journal. vol. 44, no. 4, pp. 59-76, 2013.

[19] C. X. Dai and W. G. Wells, "An exploration of project management office features and their relationship to project performance," Int. J. Proj. Manag., vol. 22, no. 7, pp. 523-532, 2004.

[20] S. Pemsel and A. Wiewiora, "Project management office a knowledge broker in project-based organisations," Int. J. Proj. Manag., vol. 31, no. 1, pp. 31-42, 2013. 
[21] B. Tshuma, H. Steyn, and C. C. van Waveren, "The role played by PMOs in the transfer of knowledge between projects: A conceptual framework,” South African J. Ind. Eng., vol. 29, no. 2, pp. 127-140, 2018.

[22] J. Julian, "How project management office leaders facilitate cross-project learning and continuous improvement," Proj. Manag. J., vol. 39, no. 3, pp. 43-58, 2008.

[23] K. C. Desouza and J. R. Evaristo, "Project management offices: A case of knowledge-based archetypes," Int. J. Inf. Manage., vol. 26, no. 5, pp. 414-423, 2006.

[24] C. C. van Waveren, L. A. G. Oerlemans, and M. W. Pretorius, "Refining the classification of knowledge transfer mechanisms for project-to-project knowledge sharing," South African J. Econ. Manag. Sci., vol. 20, no. 1, pp. 116, 2017.

[25] L. Bell, C. C. van Waveren, and H. Steyn, "Knowledge-sharing within the project-based organisation: A knowledge-pull framework," South African J. Ind. Eng., vol. 27, no. 4, pp. 18-33, 2016.

[26] M. Saunders, P. Lewis, and A. Thornhill, Research methods for business students, 7th ed. Pearson, 2016.

[27] J. Rowley, “Using case studies in research," Manag. Res. News, vol. 25, no. 1, pp. 16-27, 2002.

[28] B. Flyvbjerg, "Case study," in The Sage handbook of qualitative research, 4th ed., N. K. Denzim and Y. S. Lincoln, Eds. Thousand Oaks, 2011, pp. 301-316. 